\title{
PATTERNS OF HYPERTENSION AMONGST RURAL POPULATION AGED 13 YEARS AND ABOVE IN KANPUR, UTTAR PRADESH
}

\author{
Ashok Kr. Maini' ${ }^{1}$ Anju Gahlot², S. P. Singh ${ }^{3}$, Mainish Kr. Singh ${ }^{4}$, Ajay Bhagoliwal ${ }^{5}$
}

${ }_{1}^{1}$ Assistant Professor, Department of Community Medicine, Rama Medical College Hospital and Research Centre, Mandhana, Kanpur, Uttar Pradesh, India.

2Professor, Department of Community Medicine, Rama Medical College Hospital and Research Centre, Mandhana, Kanpur, Uttar Pradesh, India.

${ }^{3}$ Assistant Professor, Department of Community Medicine, Rama Medical College Hospital and Research Centre, Mandhana, Kanpur, Uttar Pradesh, India.

${ }_{4}^{4}$ Postgraduate Student, Department of Community Medicine, Rama Medical College Hospital and Research Centre, Mandhana, Kanpur, Uttar Pradesh, India.

5Professor, Department of Biostatistics, Rama Medical College Hospital and Research Centre, Mandhana, Kanpur, Uttar Pradesh, India. ABSTRACT

\section{BACKGROUND}

Hypertension is more prevalent in low and middle-income countries. There are also more people affected, because more people live in those countries than in high-income countries. The increasing prevalence of hypertension is attributed to population growth, ageing and behavioural risk factors such as unhealthy diet, harmful use of alcohol, lack of physical activity, excess weight and exposure to persistent stress. It is the most common CVD disorder, which poses a major public health challenge to a population undergoing socioeconomic evolution.

The objectives of the study were to determine the prevalence of hypertension and associated risk factors among rural population of Kanpur (UP).

\section{MATERIALS AND METHODS}

A randomised controlled trial study was conducted from July 2017 to June 2018 among 1410 subjects aged $\geq 13$ years who were residents of area under Rural Health Training Centre (RHTC), Mandhana block of Kanpur district and they were selected through multistage random sampling method.

\section{RESULTS}

Hypertension prevalence was $21.27 \%$ and pre-hypertension was found in $15.4 \%$ among study population. Prevalence of hypertension was significantly associated with high age group, while maximum number of subjects who were pre-hypertensive aged between (20 - 30) years. It was slightly more among the male subjects than in females. Smoking was significantly associated with hypertension. It was more prevalent among mild and sedentary lifestyle, unhealthy eating habits and association was significant with BMI $\geq 25$.

\section{CONCLUSION}

In the study, every fifth study individual is hypertensive, where smoking (tobacco in any form) and obesity was found as the commonest risk factor for it. Pre-hypertension among adolescent and young adults may be resulting from lack of exercise, eating habits, stress, increasing urbanisation and changing lifestyle.

\section{KEY WORDS}

Pre-Hypertension, Risk Factor, BMI.

HOW TO CITE THIS ARTICLE: Maini AK, Gahlot A, Singh SP, et al. Patterns of hypertension amongst rural population aged 13 years and above in Kanpur, Uttar Pradesh. J. Evolution Med. Dent. Sci. 2018;7(40):4356-4360, DOI: 10.14260/jemds/2018/972

\section{BACKGROUND}

Hypertension is more prevalent in low- and middle-income countries. There are also more people affected, because more people live in those countries than in high-income countries. Further, because of weak health systems people with hypertension who are undiagnosed, untreated and uncontrolled is also higher in low- and middle-income

'Financial or Other Competing Interest': None.

Submission 14-08-2018, Peer Review 15-09-2018,

Acceptance 21-09-2018, Published 01-10-2018.

Corresponding Author:

Dr. Ashok Kr. Maini,

\#3/198, Vishnupuri,

Kanpur, Uttar Pradesh, India.

E-mail: ashokanitamaini@gmail.com

DOI: $10.14260 /$ jemds $/ 2018 / 972$ countries compared to high-income countries.[1] The increasing prevalence of hypertension is attributed to population growth, ageing and behavioural risk factors such as unhealthy diet, harmful use of alcohol, lack of physical activity, excess weight and exposure to persistent stress.

The adverse health consequences of hypertension are compounded, because many affected people also have other health risk factors that increase the odds of heart attack, stroke and kidney failure. These risk factors include tobacco use, obesity, high cholesterol and diabetes mellitus. Hypertension is a chronic condition of concern because of its role in the causation of Coronary Heart Disease (CHD), stroke and other vascular complications. It is the most common CVD disorder, which poses a major public health challenge to a population undergoing socioeconomic evolution.[2] 
It is one of the major risk factors for CVD mortality, accounting for $20-50 \%$ of all deaths. Every fourth individual in India aged above 18 years has raised blood pressure and the prevalence has increased by $10 \%$ from 2010 to 2014.[3]

\section{MATERIALS AND METHODS}

\section{Study Design}

A randomised controlled trial study has been carried out in rural area of district Kanpur Nagar over the period of July 2017 to June 2018.

\section{Sample Size and Sampling Procedure}

Sample size was calculated using formula for determination of sample size for estimating proportions.

\section{Sample Size}

Sample size for current study was calculated using the formula-

Sample size $(\mathrm{N}) \geq$

$\mathrm{Z}^{2} 1-\alpha / 2 \times \mathrm{p} \times \mathrm{q}$

(d) ${ }^{2}$

$\mathrm{N}=$ Sample size; $\mathrm{Z}_{1-\alpha / 2}=1.96$ [Value of $\mathrm{Z}$ for $95 \%$ probability]

$\mathrm{p}=$ Prevalence; $\mathrm{q}=1-\mathrm{P} ; \mathrm{d}=$ Allowable error $(10 \%$ of Prevalence $)$

NFHS 4 data depicts the mean prevalence of blood pressure to be $22.4 \%$ (for both men and women, total of all the three categories\#).[4]

Minimum sample size $\geq 1380$ using above formula.

\section{Study Population an Overview}

Total families surveyed $=348$ with mean family size of 5.2 . Enumerated total family members $=1810$. Identified eligible respondents 1810 - 360 (19.88\% population was 13 years) $=1450$. After various exclusion criteria, 1410 respondents were interviewed and included in the study.

\section{Inclusion and Exclusion Criteria}

All family members $\geq 13$ years were included in the study with those who were willing to participate except critically ill and pregnant women and subjects who were found absent during two consecutive visits and/or not willing to participate in the study.

\section{Sampling Technique}

Multistage random sampling technique was used to select representative sample population of rural Kanpur.

\section{Sampling Technique}

Multistage random sampling technique was used to select representative sample among population of rural Kanpur.

\section{First Stage}

There are 24 villages and 4 subcentres belonging to area of jurisdiction of RHTC Shivrajpur. Two of the sub-centres were selected randomly.

\section{Second Stage}

At the second stage, 1 village was selected randomly from each of the two sub-centres. House to house survey was carried out in each of the selected villages, starting from the first house on the left. All members of the families, who voluntarily agreed to participate, in the age of thirteen years and above will be interviewed and examined to obtain the required information.

\section{Study Tools and Equipment}

Data was collected using predesigned and pretested proforma, Mercury Sphygmomanometer blood pressure measuring apparatus, calibrated electronic weighing machine and stature meter respectively.

\section{Study Technique}

Oral informed consent was taken from all the participants. Personal interview and clinical examination were done. Blood pressure (BP) recorded by mercury sphygmomanometer (Auscultatory method). Two measurements were taken at 10 minutes time interval, after persons were seated for at least 30 mins. Blood pressure measurements were made on the subject's left arm using a cuff of appropriate size at the level of the heart. Weight and height were measured by using electronic weighing machine and stature meter respectively.

\section{Study Variables}

Age, gender, educational status, occupational status, family type, socio-economic status (according to modified BG Prasad's classification), and risk factors for hypertension (Family history of hypertension, type of diet, amount of salt intake, history of alcohol intake, history of smoking, history of tobacco chewing, history of physical activity and BMI).

\section{Criteria for Diagnosis of Various Variables of the Study}

1. Hypertension diagnosed as per JNC-VII criteria.

2. Classification of hypertension for paediatric and adolescents. [Adopted from Lurbe E, Alvarez J, Redon J. Diagnosis and treatment of hypertension; hypertension reports 2010;12;480-6].

3. Body Mass Index (BMI) according to standard criteria of World Health Organization.

\section{Ethical Consideration}

Ethical clearance was taken from the Ethical Committee of Rama Medical College and Research Centre, Mandhana, Kanpur (UP). Before the interview was commenced, the purpose of the study was clearly explained to the respondents. The willingness to participate by the subjects in the study was confirmed by taking their oral informed consent. Due confidentiality was maintained by using coding system for analysis.

\section{Statistical Analysis}

Data was analysed using the SPSS version 21.0. The prevalence rates are given as percentages. Qualitative data was analysed using Pearson's Chi-square test. Continuous data were analysed using suitable statistical techniques. The p-values less than 0.05 was considered statistically significant. The data thus analysed were presented in tabular form and interpretations were made to draw important conclusions. 


\section{RESULTS}

Present study shows that overall prevalence of hypertension was $21.27 \%$. Among total $(\mathrm{N}=1410)$ respondents, 300 were found hypertensive. Further (4.7\%) were within the group, adolescents and teens aged between (13 - 19 years), rest 95.3\% respondents were adults and elderly aged ( $>20$ years). Overall prevalence of pre-hypertension was $14.5 \%$ [Table 1].

Results showing that maximum $29.7 \%$ subjects aged $>60$ years and minimum $4.7 \%$ subjects aged between $13-20$ years were hypertensive. The association between age and HTN status of subjects was found statistically highly significant $(\chi 2=17.116$; d.f. $=10 ; p=0.000)$.

Out of a total 300 hypertensives, 153 were males and 147 were females. Hypertension among males was slightly more than females, but pre-hypertension was much higher among males in our study. The association between different hypertensive stages and gender is statistically significant $(\chi 2=14.352, \mathrm{df}=2 ; \mathrm{p}=0.001)$.

Maximum $27.7 \%$ belonged to lower class and minimum $10.0 \%$ subjects belonged to upper socio-economic status. This association between socio-economic status and hypertension was found statistically significant $(\chi 2=59.241$, $\mathrm{df}=8 ; \mathrm{p}=0.000$ ).

Most of the hypertensive subjects, $80.1 \%$ were having family $\mathrm{H} / \mathrm{O}$ hypertension and $19.9 \%$ were not having any family $\mathrm{H} / \mathrm{O}$ hypertension. The association between family $\mathrm{H} / \mathrm{O}$ hypertension and hypertensive status of respondents was found to be statistically significant $(\chi 2=14.352, \mathrm{df}=2$; $\mathrm{p}=0.001$ ).

Results shows that mean SBP and DBP increases with increasing age. Mean SBP of subjects aged between $13-20$ years was $110.43 \pm 9.02$, DBP was $72.16 \pm 6.40$ and in age group $>60$ years, SBP was $133.92 \pm 23.50$ and DBP was 77.46 \pm 8.59. Mean SBP amongst female was $121.58 \pm 17.42$ and DBP was $77.49 \pm 8.96$, which was higher than males SBP $121.00 \pm 16.64$ and DBP $77.44 \pm 8.28$. Social class-II (upper middle) subjects were with highest mean SBP $126.90 \pm 15.55$, DBP $80.72 \pm 15.60$ and minimum among class-IV (Lower middle) SBP $120.24 \pm 16.20$ and DBP 76.12 \pm 8.12. Respondents with family H/O of HTN were having more SBP $132.68 \pm 20.78$, DBP $82.60 \pm 8.13$ than without family $\mathrm{H} / \mathrm{O}$ HTN SBP $121.20 \pm 17.18$ and DBP $82.60 \pm 8.13$ [Table 3]

\begin{tabular}{|c|c|c|c|c|}
\hline Group & Normotensive & Pre-HTN & HTN (Stage-I/II) & Total \\
\hline Adolescent and Teens (13 - 19) Years & $1711(19.0 \%)$ & $28(13.5 \%)$ & $14(4.7 \%)$ & $213(15.4 \%)$ \\
\hline Adults and Elderly (> 20) Years & $731(81.0 \%)$ & $180(86.5 \%)$ & $286(95.3 \%)$ & $1197(84.6 \%)$ \\
\hline Total & $902(100 \%)$ & $208(100 \%)$ & $300(100 \%)$ & $1410(100 \%)$ \\
\hline Table 1. Prevalence of HTN among Adolescent/ Teens and Adults/Elderly \\
\hline
\end{tabular}

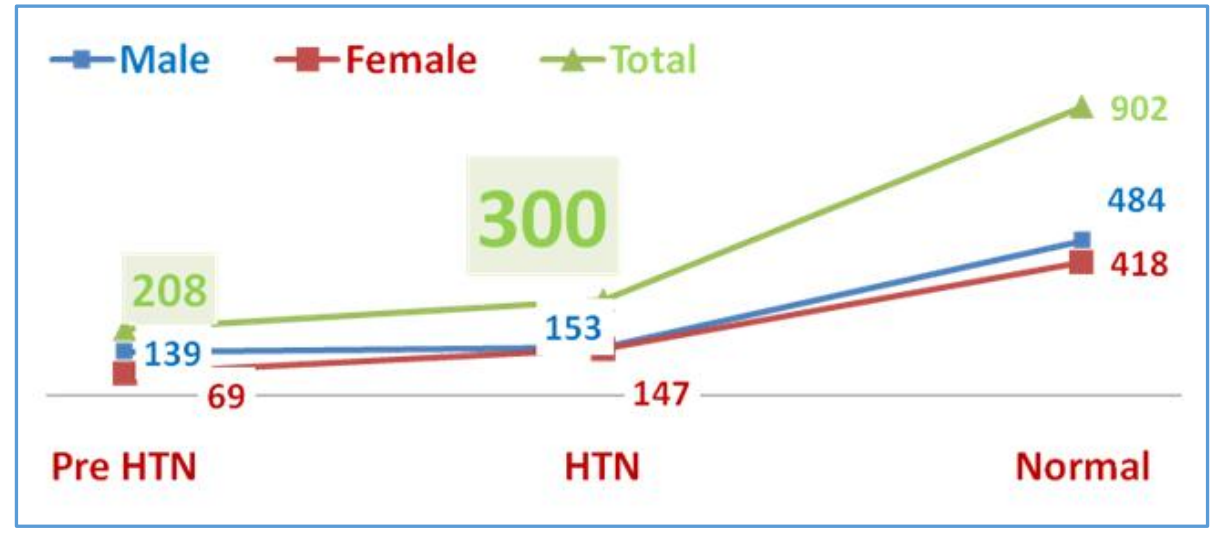

Figure 1

\begin{tabular}{|c|c|c|c|c|c|c|c|}
\hline \multirow{2}{*}{ Variables } & \multicolumn{3}{|c|}{ Hypertensive Status } & \multirow{2}{*}{ Total } & \multirow{2}{*}{ Chi-Square $(\chi 2)$} & \multirow{2}{*}{ df } & \multirow{2}{*}{$\begin{array}{c}P \\
\text { value }\end{array}$} \\
\hline & Normal & Pre-HTN & HTN & & & & \\
\hline \multicolumn{8}{|c|}{ Age Group } \\
\hline $13-20$ & $171(19.0 \%)$ & $28(13.5 \%)$ & $14(4.7 \%)$ & $213(15.1 \%)$ & \multirow{6}{*}{179.116} & \multirow{6}{*}{10} & \multirow{6}{*}{0.000} \\
\hline $20-30$ & $264(29.3 \%)$ & $6430.8 \%$ & $25(8.3 \%)$ & $353(25 \%)$ & & & \\
\hline $30-40$ & $182(20.2 \%)$ & $43(20.7 \%)$ & $56(18.7 \%)$ & $281(19.9 \%)$ & & & \\
\hline $40-50$ & $130(14.4 \%)$ & $2812.5 \%)$ & $56(12.5 \%)$ & $212(15.0 \%)$ & & & \\
\hline $50-60$ & $60(6.7 \%)$ & $21(10.1 \%)$ & $60(20.0 \%)$ & $141(10.0 \%)$ & & & \\
\hline$>60$ & $95(10.5 \%)$ & $26(12.7 \%)$ & $89(29.7 \%)$ & $210(14.9 \%)$ & & & \\
\hline \multicolumn{8}{|c|}{ Gender } \\
\hline Male & $484(53.7 \%)$ & $139(66.8 \%)$ & $153(51.0 \%)$ & $776(55.0 \%)$ & \multirow{2}{*}{14.352} & \multirow{2}{*}{2} & \multirow{2}{*}{0.001} \\
\hline Female & $418(46.3 \%)$ & $69(33.2 \%)$ & $147(41.0 \%)$ & $634(45.0 \%)$ & & & \\
\hline \multicolumn{8}{|c|}{ SES } \\
\hline Class-I & $94(10.4 \%)$ & $21(10.1 \%)$ & $39(13.0 \%)$ & $154(10.5 \%)$ & \multirow{5}{*}{59.241} & \multirow{5}{*}{8} & \multirow{5}{*}{0.000} \\
\hline Class-II & $92(9.1 \%)$ & $56(26.9 \%)$ & $45(15.0 \%)$ & $183(13.0 \%)$ & & & \\
\hline Class-III & $250(27.7 \%)$ & $42(20.2 \%)$ & $89(29.7 \%)$ & $381(27.0 \%)$ & & & \\
\hline Class-IV & $19721.7 \%)$ & $37(17.8 \%)$ & $65(21.7 \%)$ & $299(21.2 \%)$ & & & \\
\hline Class-V & $279(30.9 \%)$ & $62(25.0 \%)$ & $52(20.9 \%)$ & $393(27.7 \%)$ & & & \\
\hline \multicolumn{8}{|c|}{ Family H/O HTN } \\
\hline
\end{tabular}




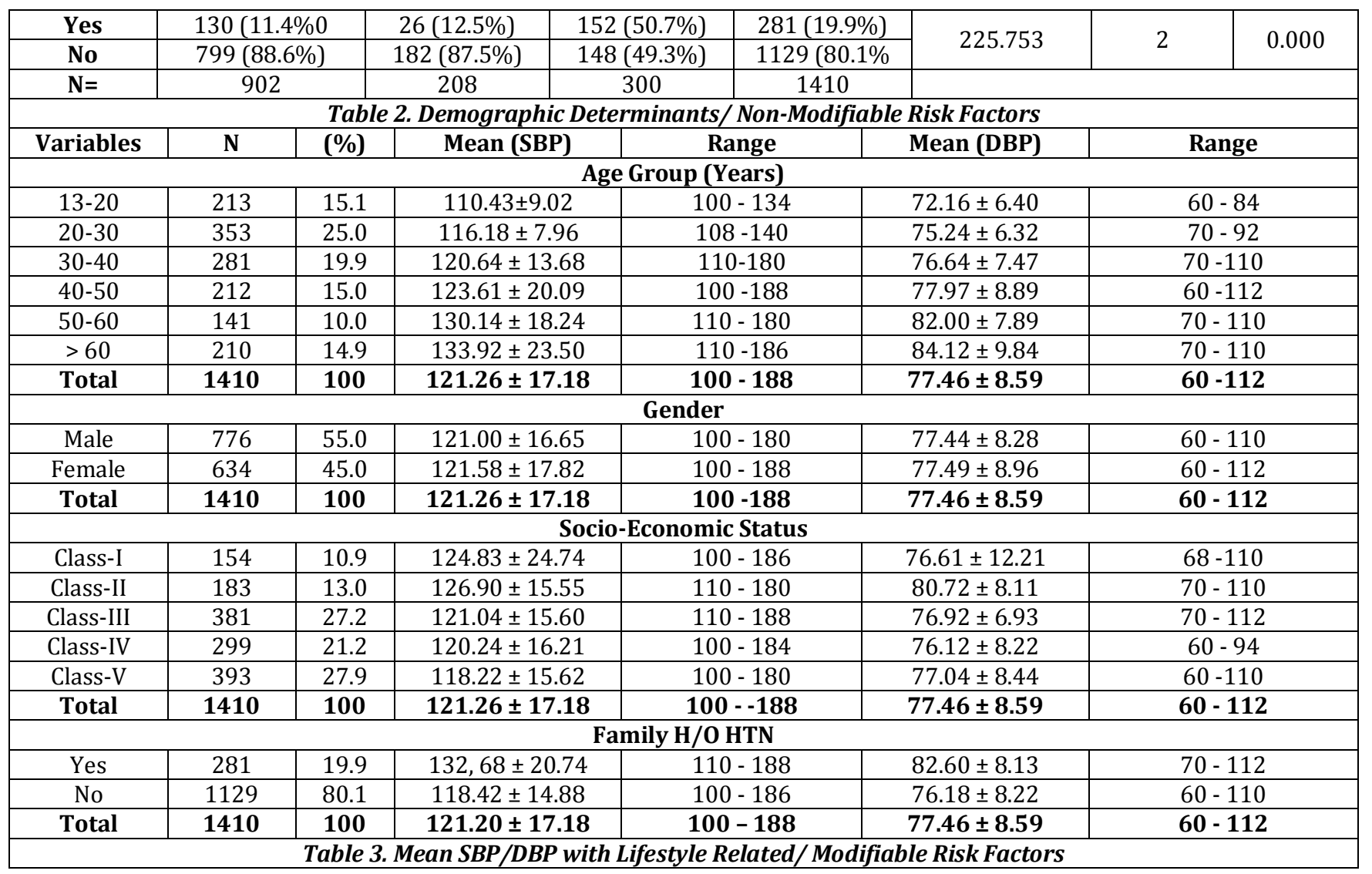

\begin{tabular}{|c|c|c|c|c|c|c|c|c|}
\hline \multirow{2}{*}{ Risk Factors } & \multirow{2}{*}{ B } & \multirow{2}{*}{ SE } & \multirow{2}{*}{ Wald } & \multirow{2}{*}{ df } & \multirow{2}{*}{ Sig. } & \multirow{2}{*}{ OR } & \multicolumn{2}{|c|}{ 95\% CI for OR } \\
\hline & & & & & & & Lower & Upper \\
\hline Diet & .522 & .132 & 15.535 & 1 & .000 & 1.686 & 1.300 & 2.185 \\
\hline Smoking Chewing Tobacco & -.501 & .139 & 12.942 & 1 & .000 & .606 & .461 & .796 \\
\hline Mild/ Moderate (Alcohol Intake) & -.147 & .189 & .606 & 1 & .436 & .863 & .597 & 1.250 \\
\hline Heavy (Alcohol Intake) & .371 & .157 & 5.609 & 1 & .018 & 1.449 & 1.066 & 1.970 \\
\hline Excess Salt Consumption & -.667 & .151 & 19.441 & 1 & .000 & .513 & .381 & .690 \\
\hline Physical Activity & .560 & .167 & 11.242 & 1 & .001 & 1.750 & 1.262 & 2.428 \\
\hline BMI Range & 1.229 & .152 & 65.215 & 1 & .000 & 3.419 & 2.537 & 4.608 \\
\hline Constant & -.758 & .232 & 10.717 & 1 & .001 & .469 & & \\
\hline
\end{tabular}

a. Variable(s) entered on Step 1: Diet, Smoking Chewing Tobacco, Mild/Moderate and Heavy (Alcohol Intake), Excess Salt

Consumption, Physical Activity, BMI range

\section{Table 4. Logistic Regression Analysis of Lifestyle Related/Modifiable Risk Factors}

\section{DISCUSSION}

In the present study overall prevalence of hypertension was found to be $21.27 \%$, which is similar to NFHS 4 survey carried out in India (2012 - 14).[5] Prevalence was found slightly more among males. Hypertension among adolescent/ teens aged (13 - 19) years was $4.7 \%$, only 14 subjects out of total 300 were found hypertensive. Prevalence of prehypertension was $14.5 \%$, which was maximum $30.8 \%$ in age group (20 - 30) years. In various paediatric hypertension studies based on the use of $\geq 95$ th percentile to define hypertension, it would be expected that the prevalence of hypertension would be approximately 5\%. In a crosssectional study limited to the adolescent age, the prevalence of pre-hypertension and hypertension was determined in a cohort of 6,790 high school students (11 - 17 years). Using the recommended repeated BP measurements on those with an elevated initial BP measurement, the authors found that the prevalence of hypertension was $3.2 \%$ and the prevalence of pre-hypertension was $15.7 \%$ in adolescence. Another analysis of the same two data cohorts demonstrated an overall increase in the prevalence of hypertension from $2.7 \%$ in the 1988 - 1994 survey to $3.7 \%$ in the $1999-2002$ survey.[6] Both analyses indicate that the increase in BP among children and adolescents was largely due to the increase in obesity.

Prevalence of hypertension amongst various age groups was found similar in another study done by Laxmaiah et al, risk of hypertension was nearly 2 and 5 times higher among $\geq 60$ yrs. old subjects than subjects aged 20 - 35 yrs.[7] Prevalence within income groups was maximum among high income group (Class-I) individuals and difference was statistically significant, similar to the study of Kashyap et al who found higher prevalence of hypertension among subjects of higher socio-economic status in rural areas.[8] Similarly, Naresh et al also found positive family history was strongly associated with hypertension in rural population. ${ }^{[9]}$

Results showed hypertension among study subjects with modifiable risk factors in the present study. Smoking is significantly associated with hypertension in this study. Mandani et al also found that smoking was significantly 
associated with hypertension among the tribal population of Gujarat.[10] Alcohol consumption associated with high prevalence of hypertension and this result was similar to Manimunda and Meshram et al[11] study in tribal population. In the present study, there is high prevalence among sedentary and mild worker. The difference is statistically significant. Kandpal et al also found significant correlation of hypertension with activity. [12]

BMI > 25 was significantly associated with hypertension. Gupta VK et al also found high prevalence of hypertension among overweight and obese tribals similar to this study.[13]

\section{Limitations}

The design effect was not considered for sample size, which was supposed to be taken for cluster/stratified sampling.

\section{CONCLUSION}

Detection of pre-hypertension and hypertension in the adolescent age group is a significant finding of the study. Implementing population-wide policies to reduce behavioural risk factors including harmful use of alcohol, physical inactivity, overweight, obesity and high salt intake is essential in attaining the target of reducing the burden of hypertension. A total-risk approach needs to be adopted for early detection and cost-effective management of hypertension in order to prevent heart attacks, strokes and other complications.

\section{REFERENCES}

[1] World Health Day 2013. Global Burden of Hypertension 2013. http://www.who.int/cardiovascular_diseases/publica tions/global_brief_hypertension/en. Accessed on 4, July 2017. 2 .

[2] Campbell NRC, Lackland DT, Niebylski ML, et al. High blood pressure: why prevention and control are urgent and important - a 2014 fact sheet from the World Hypertension League and the International Society of Hypertension. J Clin Hypertens (Greenwich) 2014;16(8):551-3.

[3] Sreejith PS, Kirankumar VS. A study on prevalence of hypertension among adults aged 20-70 years in Vencode, Kerala, India. Int J Intg Med Sci 2016;3(7):350-52.
[4] Kaur K, Aeri BT. Hypertension in India: an insight into the NFHS - 4 data. International Journal of Scientific and Research Publications 2017;7(7):539-43.

[5] National Family Health Survey (NFHS-4) 2012-14. Mumbai: International Institute for Population Sciences (IIPS) and Macro International: 2009. [Last accessed on 21 may 2017]. http://www.rchiips.org/nfhs/nfhs4.shtml

[6] Falkner B. Hypertension in children and adolescents: epidemiology and natural history. Pediatr Nephrol 2010;25(7):1219-24.

[7] Laxmaiah A, Meshram II, Arlappa N, et al. Socioeconomic \& demographic determinants of hypertension \& knowledge, practices \& risk behavior of tribals in India. The Indian J Med Res 2015;141(5):697-708.

[8] Kashyap V, Kumar C, Haider S, et al. Prevalence of hypertension and its association with selected sociodemographic factors in a rural area of Jharkhand. IOSR Journal of Dental and Medical Sciences (IOSR-JDMS) 2015;14(4):1-6.

[9] Naresh M, Viral S, Sudham K, et al. Assessment of risk factors of hypertension: a cross-sectional study. J Evol Med Dent Sci 2012;1(4):519-26.

[10] Mandani B, Vaghani B, Gorasiya $M$, et al. Epidemiological factors associated with hypertension among tribal population in Gujarat. Natl J Community Med 2011;2(1):133-5.

[11] Manimunda SP, Sugunan AP, Benegal V, et al. Association of hypertension with risk factors \& hypertension related behaviour among the aboriginal Nicobarese tribe living in Car Nicobar Island, India. The Indian Journal of Medical Research 2011;133(3):287-93.

[12] Kandpal V, Sachdeva MP, Saraswathy KN. An assessment study of CVD related risk factors in a tribal population of India. BMC Public Health 2016;16(1):434.

[13] Gupta VK, Rai N, Toppo NA, et al. An epidemiological study of prevalence of hypertension and its risk factors among non- migratory tribal population of Mawai block of Mandla district of central India. Int J Community Med Public Health 2018;5(3):957-62. 